\title{
Searches for a Nursing Home: Personal and Situational Factors
}

\author{
Shirley S. Travis \\ William J. McAuley \\ University of Oklahoma
}

Telephone and follow-up in-depth interviews were used to gather information from 25 sponsors (primary contact people or responsible parties) of nursing home residents to learn more about the nursing home search and selection process. Quantitative analyses revealed that sponsors who engaged in anticipatory action prior to the need for nursing home placement had lower personal competence scores than those sponsors who did not anticipate the need for nursing home care. As might be expected, sponsors who were involved in time-pressured searches had the highest stress scores. In-depth analyses of the qualitative data illuminated the diverse ways in which the situational factors (time-pressured versus non-time-pressured searches and anticipatory versus nonanticipatory behavior) affected the personal factors (perceived competence and stress) to create idiosyncratic experiences for the sponsors. The findings show the value of offering professional assistance to individuals who are at the stage of seeking information about nursing homes.

Prior research has established that nursing home placement is actually a very complex decision-making process (see Gonyea, 1987; Groger, 1994), precipitated by diverse triggers and reasons for making the decision to enter a nursing home (Freudenberger Jett, Coward, Schoenberg, Duncan, \& Dwyer, 1996). Less well understood are the real world experiences of the people who actually go about searching for and selecting a nursing home. Similarly, it is not known what effect certain situational factors have on the searchers' personal responses to the experience.

Qualitative analysis of sponsors' "search stories" (McAuley, Travis, \& Safewright, 1997) and quantitative analyses of positions of influence in the search process (McAuley \& Travis, 1997) have been previously reported. This article explores the ways in which two situational factors (timepressured versus non-time-pressured searches and anticipatory versus

AUTHORS' NOTE: Research supported by a grant from the AARP Andrus Foundation.

The Journal of Applied Gerontology, Vol. 17 No. 3, September 1998 352-370

(C) 1998 The Southern Gerontological Society 
nonanticipatory search patterns) are related to personal factors (perceived personal competence and perceived level of stress) of the sponsors. To accomplish this task, both quantitative data (based on telephone interviews) and qualitative data (based on in-depth, face-to-face interviews) were used simultaneously to permit a richer understanding of both the shared and the idiosyncratic experiences of the sponsors (Floyd, 1993; Holstein, 1995; Reinharz \& Rowles, 1988). In this study, the term sponsors is used to indicate individuals who are identified as primary contact people or responsible parties for residents recently admitted to a nursing home, some of whom were searching on behalf of individuals who were not related by blood or marriage.

\section{Review of Relevant Literature on Situational and Personal Factors}

\section{Anticipatory Versus Nonanticipatory Search Behavior}

Two types of sponsors are likely to be engaged in a search and selection process: (a) those who expected an eventual need for placement, either because they were already engaged in long-term caregiving or had seen a gradual deterioration in a care recipient's functional status; and (b) those who had no prior warning about the potential need for nursing home care (Freudenberger Jett et al., 1996; Gonyea, 1987). In the case of sponsors who expected eventual nursing home placement, some are likely to act on their assessments of the long-term care situation, whereas others do nothing to prepare for an eventual nursing home admission.

Although there is no literature specifically addressing the anticipatory/nonanticipatory behavioral dichotomy described above, prior research has suggested that nursing home decisions are easier for family caregivers of individuals who are experiencing declines in both physical and mental functioning and who prepare for eventual long-term care placement (Chenoweth \& Spencer, 1986; George \& Gwyther, 1986; Pratt, Schmall, \& Wright, 1987; Salamon \& Rosenthal, 1990). Therefore, we might expect more competent sponsors to be among current caregivers or responsible others who make an effort to educate themselves about or otherwise engage in preparation for nursing home care. Conversely, sponsors who have no prior warning about the need for placement or choose not to take any anticipatory action would feel less personal competence in the placement process. The literature suggests that this latter group may include sponsors who struggle with the reality that they are no longer able to continue their current caregiving 
arrangement and are reluctant to make long-term care placement decisions (Salamon \& Rosenthal, 1990), sponsors who are simply too overwhelmed with daily caregiving hassles to think about a long-term care plan (Noelker \& Townsend, 1987), and those who had no warning that a nursing home placement would be needed.

Many stress researchers assert that stress is a dynamic process that is best determined by the individual based on his or her own cognitive appraisal of an event (Lazarus \& DeLongis, 1983). Something that is not perceived as disturbing will not elicit stress (Stagner, 1981). As others have pointed out, one of the most perplexing problems about stress is the high degree of variability found in people's responses to potentially stressful events and the high degree of intraindividual variation of responses to the same type of event at different times (Stephens \& Hobfoll, 1990). Of the two groups previously described, it is not known whether caregivers who engaged in anticipatory behavior would have greater or lower levels of stress than their nonanticipatory counterparts. However, it is widely held that those who take charge of stressful situations are most successful at alleviating distress (Stephens \& Hobfoll, 1990). Therefore, those sponsors who engage in some prior preparation for an eventual nursing home placement should report lower levels of perceived stress during the search and selection process than those who do not.

\section{Time-Pressured Versus Non-Time-Pressured Searches}

Among nursing home sponsors, hospitalization is one of the principal triggers for nursing home searches (Kane \& Kane, 1989) and represents a significant crisis in the lives of elders and their caregiving systems (Coulton, Dunkle, Haug, Chow, \& Vielhaber, 1989). Because the current method of hospital reimbursement for Medicare and Medicaid patients contains intrinsic incentives for rapid discharge from acute care, families in need of posthospital care often find themselves pushed for a placement decision over a matter of just a few days. Therefore, sponsors who search for nursing home placements as a result of hospitalization generally experience time pressure to make decisions, whether or not long-term care had been an issue before the hospital admission. Similarly, caregivers who are forced to make quick transitions in the level of care currently being provided in the home or the community would also be in a time pressure situation. In contrast, sponsors who are engaged in self-paced searches with no external pressures to make a decision and who have a healthy emotional relationship with the care recipient (Pratt, Schmall, Wright, \& Hare, 1987) would be less likely to be 
pressured. Because pressure to make decisions quickly offers little opportunity to develop knowledge and skill in long-term care searches, it follows that those sponsors who experience time pressures could feel less competent and have greater perceived stress than those who engage in the nursing home search and selection process with no external time pressures.

\section{Method}

\section{The Sample}

The sample consisted of 25 sponsors of recently admitted nursing home residents. The sponsors were selected from an original sample of 150 sponsors who were recruited for the study with the help of 79 cooperating nursing homes located in the eastern United States. Unlike most earlier studies, which did not make efforts to limit time since the search and selection process, the study identified individuals whose time since placement on a waiting list or combined time on the waiting list and admission was brief enough (within 90 days) to permit reasonable retrospective descriptions of the search and selection process.

An advance letter was mailed to all potential respondents to let them know that someone would be telephoning them soon about the study. Out of a total of 192 potential cases, 150 agreed to the telephone interview, for a response rate of $78 \%$. Following a telephone survey of the original 150 sponsors, in-depth interview participants were selected to provide diversity across geographic locations in the state, rural and urban environments, sponsor-resident dyad types (e.g., adult child/parent, spouses, siblings, adult grandchild/grandparent, friend/friend), and ages of the residents. The mean age of the sponsors was 59 , with a range of 31 to 90 years. The mean age of the residents was 81.4 , with a range of 70 to 100 years. Because Blacks and males tend to be underrepresented in the caregiving literature, oversampling occurred among Blacks and male sponsors such that $20 \%$ of the sample $(n=5)$ was Black and $40 \%(n=10)$ was male. Although nearly all of the potential respondents were willing to participate in the in-depth interview, several were unable to find a time to schedule it. In addition, a few indicated that the earlier search and selection process had been very stressful and that they would rather not be reminded of the experience. In all, project staff contacted 31 individuals to obtain approval from the 25 who completed the in-depth interviews, for a response rate at this stage of $81 \%$. 


\section{Data Collection}

The initial telephone interviews were completed by trained interviewers at a university survey research laboratory. The survey asked sponsors an array of questions dealing with individual and interpersonal factors (e.g., who was involved and their levels of influence, the functional status of the care recipient, competing demands on the sponsor during the process, and the sponsor's personal assessment of the process), factors that were important in the decision to seek nursing home care, sources of information available to the searchers and decision makers, financial issues, the availability of nursing homes versus the number of facilities actually considered and visited, and characteristics of the nursing homes that the sponsors believed to be important in making a final selection.

The in-depth interviews were completed by members of the research team during a 5-month period following the telephone interviews. Most in-depth interviews were carried out in the home of the respondent; however, one took place in a restaurant, and one was conducted by telephone because the respondent wanted to participate in the interview, but a convenient face-toface interview time could not be found. Although a semistructured interview guide was developed for each sponsor, based on responses to the telephone survey, the goal was to have the respondents tell the story of their experiences in their own words. The interviews generally required from 1 hour and 15 minutes to $1 / 2$ hours to complete. With the respondents' permission, all interviews were taperecorded for subsequent transcription into a word processing program.

\section{Variables Obtained From the Quantitative Data}

Personal competence. Respondents were asked the degree to which they agreed or disagreed (strongly agree $=4$, somewhat agree $=3$, somewhat disagree $=2$, strongly disagree $=1$ ) with three items selected to measure personal competence: effort appreciated by others, felt well informed, and did everything I could. Responses were summed across the three items to yield a personal competence score such that high scores represented greater personal competence (Cronbach's alpha $=.74$ ).

Level of stress. Respondents were asked the degree to which they agreed or disagreed (strongly agree $=4$, somewhat agree $=3$, somewhat disagree $=$ 2 , strongly disagree $=1$ ) with four items selected to measure stress during the process: crisis in my life, experience was confusing, experience was 
stressful, and felt guilty. Responses were summed across the four items to yield a stress score such that high scores represented greater personal stress $($ Cronbach's alpha $=.74)$.

\section{Variables Constructed From the Qualitative Data}

The qualitative data provided a means for creating personal and situational variables that had not been included in the original quantitative data set. Each transcript was reviewed to determine whether the sponsor searched in a timepressured or non-time-pressured mode and whether the sponsor had anticipated the need for institutional care prior to the time that nursing placement became a reality. Thus, we were able to develop mutually exclusive categories for each search situation on two dimensions according to whether the search (a) occurred under time-pressured circumstances and (b) involved anticipatory activity.

Time-pressured versus non-time-pressured searches. Respondents were determined to be in a time-pressured search if the need for nursing home admission occurred as a result of hospitalization or the respondent described pressure to place the resident from an existing caregiving situation to institutional care. For example, if the resident was in day care and the staff had given the family notice of pending discharge, the search was considered time limited and a time-pressured search.

Anticipatory behavior. A respondent was considered to have engaged in anticipatory searching behavior if he or she obtained information about any element of institutional long-term care placement prior to the time that the need for institutionalization was a certainty. This information could include, but was not limited to, gathering information about or engaging in preliminary planning regarding nursing homes, legal issues, cost of care, or Medicaid eligibility requirements.

\section{Data Analysis}

First, we labeled each case according to whether the search was a timepressured or non-time-pressured search and whether the sponsor had engaged in anticipatory search activity prior to the need for a nursing home admission. The resulting fourfold typology was used to organize the cases into search categories: Time-Pressured/Nonanticipatory, Time-Pressured/ AnticipatoryNon-Time-Pressured/Nonanticipatory, and Non-Time-Pressured/Anticipatory. 
Table 1. Sponsor-Resident Characteristics, Competence, and Stress Scores by Type of Nursing Home Search

\begin{tabular}{|c|c|c|c|c|}
\hline $\begin{array}{l}\text { Characteristic and } \\
\text { Personal Factors } \\
\text { Scores }\end{array}$ & $\begin{array}{c}\text { Time- } \\
\text { Pressured/ } \\
\text { Anticipatory } \\
\mathrm{n}=8\end{array}$ & $\begin{array}{c}\text { Time- } \\
\text { Pressured/ } \\
\text { Nonanticipatory } \\
\mathrm{n}=10\end{array}$ & $\begin{array}{c}\text { Non-Time- } \\
\text { Pressured/ } \\
\text { Anticipatory } \\
n=6\end{array}$ & $\begin{array}{c}\text { Non-Time- } \\
\text { Pressured/ } \\
\text { Nonanticipatory } \\
\mathrm{n}=1\end{array}$ \\
\hline Average resident age & 82 & 81 & 80 & 95 \\
\hline $\begin{array}{l}\text { Average sponsor age } \\
\text { Sponsor gender- } \\
\text { percentage }(n)\end{array}$ & 51 & 60 & 68 & 62 \\
\hline Male & $38(3)$ & $40(4)$ & $50(3)$ & \\
\hline Female & $62(5)$ & $60 \%(6)$ & $50(3)$ & $100(1)$ \\
\hline Race-percentage $(n)$ & & & & \\
\hline White & $75(6)$ & $90(9)$ & $67(4)$ & $100(1)$ \\
\hline Black & $25(2)$ & $10(1)$ & $33(2)$ & \\
\hline $\begin{array}{l}\text { Sponsor categories- } \\
\text { percentage }(n)\end{array}$ & & & & \\
\hline $\begin{array}{l}\text { Spouses } \\
\text { Adult child for }\end{array}$ & & $20(2)$ & $50(3)$ & \\
\hline $\begin{array}{l}\text { parent } \\
\text { Siblings } \\
\text { Other family }\end{array}$ & $75(6)$ & $\begin{array}{l}30(3) \\
20(2)\end{array}$ & $16.1(1)$ & \\
\hline relations & $12.5(1)$ & $30(3)$ & $16.6(1)$ & $100(1)$ \\
\hline $\begin{array}{l}\text { Friends } \\
\text { Average competence }\end{array}$ & $12.5(1)$ & & $16.6(1)$ & \\
\hline score & 9.8 & 11.4 & 10.8 & 10 \\
\hline Average stress score & 13.3 & 11.1 & 10.7 & 5 \\
\hline
\end{tabular}

Summaries of the resident/sponsor characteristics according to this typology can be found in Table 1. A content analysis was then completed to explore similarities and differences in their individual and group search and selection experiences.

Next, we computed competence and stress scores in the manner described and added them to Table 1 . A series of $t$ tests were computed to compare mean scores for males versus females, Whites versus Blacks, sponsors in timepressured versus non-time-pressured searches, and sponsors engaged in anticipatory versus nonanticipatory searches. Because of the small sample size, the level of significance was set at .10 . Based on the review of the literature, all of the comparisons, with the exception of gender and race, permitted tests of directional hypotheses. Gender and race differences had not been previously examined. However, because we oversampled on Blacks 
and men, we were able to perform $t$ tests to be sure that no differences existed for these two sponsor characteristics. Unless otherwise specified, all analyses used one-tailed tests of significance. Finally, we reviewed each transcript from the in-depth interviews to observe the ways in which the situational factors in the individual stories clarified or confounded the results of the $t$ tests.

\section{Results}

\section{Situational Factors}

Of the sponsors, $72 \%$ percent $(n=18)$ were involved in time-pressured searches. They were about equally divided between those who had engaged in anticipatory behavior $(n=8)$ and those who had not $(n=10)$. Of the remaining $28 \%$ of the sample $(n=7)$, who were non-time-pressured searchers, all but one had engaged in anticipatory behavior prior to the need for nursing home placement.

Time-pressured/anticipatory searches. It is noteworthy that 6 of the 8 sponsors in this group were adult children searching on behalf of a parent. In every case, the 8 sponsors were already engaged in some aspect of long-term caregiving for the nursing home resident and had already determined that the resident would eventually need assistance beyond the sponsor's means and capabilities before time came to make the nursing home placement. Accounts of the caregiving arrangement by a daughter, who was searching on behalf of her mother, were typical of the other time-pressured/ anticipatory searchers. She stated,

Mother has Alzheimer's disease and I had a lady that stayed with her during the daytime and put her to bed at night. And then we had to go to 24 hours. I really didn't want to put her in, you know, until I really had it. ... I was working and it got to be pretty rough doing nights ... and working in the daytime.

Her time-pressured search occurred when her mother fell and broke her pelvis. The hospital discharge plan required nursing home care and the sponsor "had to do something very quickly."

The complex family dynamics that many of these sponsors experienced were apparent in the remarks of another caregiving daughter. She described with some passion the years of care she had provided to her frail, incontinent father and her growing frustration with being his primary caregiver. 
I lived with dad 18 years because I married young. I've lived with [her husband] 30 years. Why do we feel this guilty toward our parents? Why is it so strong a feeling that I feel like I have to bring him in my home, let him mess up my carpet, let him ruin my life, tell me what to do, tell me who I can see. I mean the day of my daughter's wedding he refused to go. I left him here [her home] with a nurse. He called me during the reception for an emergency.

She went on to explain that she finally made the decision for nursing home care when her father took her car keys and tried to drive away in her car. $\mathrm{He}$ had experienced several bouts with pneumonia requiring hospitalization in the months prior to the car episode, and she felt that she needed to admit him to a nursing home as soon as possible to protect her own mental health and his safety.

Time pressured/nonanticipatory. This search category contained 10 sponsors, including two spousal dyads, three adult child/parent dyads (all sons), and two sibling dyads. The remaining three sponsor/resident dyads were among our unusual sponsor categories and consisted of women searching on behalf of a grandmother, a husband's aunt (who had raised him), and a mother-in-law. All of the searches in this group were precipitated by a hospital admission. Consequently, these individuals were among the most distressed sponsors interviewed, as they recalled the crisis events surrounding the hospitalization, enormous time pressures imposed by hospital discharge planners, and their total lack of preparedness for nursing home placements. One of the more graphic stories was shared by a husband who was searching on behalf of his wife following complicated abdominal surgery. He described the mental and physical exhaustion that families experience when faced with an emergency hospitalization and the confounding distress imposed by a system that failed to help him plan for posthospital care. He said,

Well, she was taken sick on Sunday evening ... and she kept getting worse, and I called the rescue squad to come and carry her to the hospital. [The doctor] said operating would do no good at all. [Five days later another doctor] said he thought he could (operate) and she'd be allright. That wound was wide open, after he operated on her, he stapled, where he put staples in there, got infected and he had to take them out, and she had a hole in the, up here in her stomach, almost 3 inches each way. [Twelve days after surgery] the doctor said he was releasing her the next morning. I said, "Well, doctor you hadn't given me any notice, any prior notice or nothing." I said, "I' $m$ in no condition, I don't know what to do. I can't handle her at home." He says, "Well, maybe you can get her in a nursing home." So he went on, he said, "I' $m$ gonna release her anyway." So he did. 
Those sponsors in the group who appeared to be least distressed by the process were the two sibling dyads (sisters searching on behalf of sisters). Because siblings are often old themselves, they seemed to understand the limits of being cared for by another and were more accepting than others in their group of the need for nursing home care following serious hospital admissions. As one 72-year-old sister, explained,

I felt terrible at first. I didn't want to take her to the nursing home. And the first time that they mentioned nursing home, I said "No, no nursing home. I'm gonna take her home." But I found out I was wrong, and the doctor, she talked to me, and the social worker talked to me. And they told me that she would definitely have skilled care; and the doctor told me that ... I won't be able to do it. And even if my health was able, I couldn't do what was gonna have to be done. She was going to have to be put in a nursing home for a while... The doctor told me to just think about where I wanted to take her and that she was gonna send the social worker to talk to me and she would help me find somewhere.

Non-time-pressured/anticipatory. Three spousal dyads, as well as a daughter searching on behalf of her mother, a man searching on behalf of his mother-in-law, and one friend searching on behalf of a neighbor made up this sponsor group. All of their searches tended to last several months as they gathered information, visited facilities, and prepared for eventual nursing home placement decisions. Of course, not all of the search experiences were without distress. For example, a daughter whose mother was experiencing gradual decline from Alzheimer's disease attributed the breakup of her marriage to her caregiving duties for her mother. "My husband couldn't take it so he left us," she stated.

For the most part, these sponsors were very organized and methodical about their decisions. A 68-year-old spouse who was the primary caregiver for her demented husband needed eye surgery and decided to place her husband in a nursing home while she recovered. Ultimately, the decision was made to make his stay permanent. In describing the initial placement decision, she explained,

Sometimes you just have to take a hold of things in order to make things work out, so I had to. It was nothing unlikable about it, it's just one of those things you have to go through. ... Everything just went together. I started about 2 or 3 months before time that I knew I was going to be going to [the hospital].

In another case, a 100-year-old woman who had only a niece in her immediate family was fortunate to have neighbors who "took care of her for 
30 years." One of these neighbors had Durable Power of Attorney and arranged for a companion to help the elderly woman with her personal care. About 2 years before the nursing home placement, the neighbors realized that the woman needed someone to stay with her at night, and they made those arrangements, as well. The friend knew that money was getting low and that the elderly woman's condition was declining rapidly. That is when four neighborhood families became involved in the search and selection process with the niece. The sponsor seemed to have a strong sense of personal satisfaction, as she reported the caring and methodical way in which their non-time-pressured/anticipatory search helped the elderly woman to relocate to a nursing home. But she commented, "I didn't realize that having the Power of Attorney would be so time consuming."

Non-time-pressured/nonanticipatory. Only one sponsor was placed in this group. This individual was a woman who had promised her husband, deceased 12 years earlier, that she would always look out for his parents. When the sponsor retired and moved out of state, she felt obligated to move her surviving mother-in-law with her. The sponsor's major source of distress was in making the decision to move out of state to be closer to her adult children. Once her relocation process was complete, she began to implement a relocation plan for her mother-in-law. She explained,

The upshot of it was, she was by herself, and I finally decided, you know, we were obviously not gonna die too soon. She could live to be 100,110 , you know, there's no reason why she can't. She's got congestive heart failure, but they give her medication and her heart's fine. So, she's not going anywhere. And I was close to, I'm 62 now, I just moved last year, so that was 61 . And I figured I could keep an eye on her here. And I was able to find [name of facility], which is very nice. I felt, I knew her, but I always, I never understood her, let's put it that way. And it's just so ironic that I'm the one with her.

\section{Personal Factors}

Personal competence. The scores for personal competence across all search categories ranged from 3 to 12 , with an average score of 10.68 $(S D=2.04)$. On average, male sponsors reported similar personal competence (mean $=11.0, S D=1.67$ ) to female sponsors (mean $=10.43, S D=2.31$; $p=.50$, two-tail test). No difference was found between Black sponsors (mean $=$ $11.40, S D=.89)$ and White sponsors (mean $=10.50, S D=2.21) ;(p=.38$, two-tail test).

Surprisingly, the average personal competence score for those sponsors who engaged in anticipatory behavior, with or without time pressure, $(n=14)$ 
was lower (mean $=10.21, S D=2.55)$ than the average score of $11.27(S D=.90)$ for those sponsors who did not engage in anticipatory behavior $(n=11, p=.08)$. In fact, the three sponsors who scored the lowest on personal competency had all engaged in anticipatory behavior prior to the placement decision. The most frequent behaviors associated with anticipatory action included contacting nursing homes in the immediate area for literature about services, arranging for an on-site tour, or contacting the local social services department for information about Medicaid eligibility.

To better understand the association between personal competence and anticipatory behavior, attention was turned to the issue of time-pressured searches. In the aggregate, personal competence scores for sponsors who searched under time pressures $(n=18$; mean $=10.67, S D=2.14$ ) were almost identical to those sponsors who searched in non-time-pressured situations $(n=7$; mean $=10.71, S D=1.89, p=.48)$. However, when the individual stories of sponsors with low personal competence scores were examined, the rather poignant aspects of their stories suggested that time pressures most surely influenced their individual levels of personal competence. For example, a 55-year-old woman reflecting on the process of placing her terminal 74-year-old mother in a nursing home after several hospitalizations in a short period of time remarked,

The doctors told me, "your mother cannot go home, you cannot take care of her without nurses around the clock." So, we began this tedious search for a nursing home. I had done some preliminary [inquiry] before this time, but ... those last few weeks it was just everyday. We called. We talked. The social services at the hospital tried to help.

A 57-year-old man who was searching on behalf of his demented 88-yearold widowed father explained that his prior knowledge about long-term care was derived in part from experiences he had when his mother required nursing home care 10 years earlier. When his father's condition began to deteriorate and adult day services were used, the son felt familiar with the process of Medicaid eligibility and service applications. But, as he explained, when the social workers told him that his father was being discharged because of excessive behavioral problems and a rapidly deteriorating condition that required a secured care environment, "Now this is when you jump off the edge."

The effect that time pressures had on sponsors' high personal competence scores, as revealed in their stories, was not clear in part because sponsors with high scores $(n=12$ sponsors with maximum scores of 12$)$ represented every type of anticipatory versus nonanticipatory and time-pressured versus non- 
time-pressured search. One particularly interesting dyad consisted of a 31year-old man who was searching on behalf of his 82-year-old grandmother. This young sponsor, the youngest in the sample, had one of the highest personal competence scores (and one of the lowest stress scores) in the study. He explained that he had discussed nursing home care with his grandmother in the past, and she had preselected a facility because she had friends there. Her time-pressured search was precipitated by hospitalization and was confounded by the fact that the sponsor was already caring for his dependent father and could not also take on the care of his grandmother. He said,

Well, naturally me and [his wife] couldn't take care of her.... We've never been a family of any type of wealth. ... And of course I have a problem with having my dad. I think I have almost exhausted my leave [from work].

Despite the fact that tremendous caregiving responsibility had fallen to this young caregiver, he seemed to feel good about his ability to make the right decisions and get the help he needed to handle the situation. One clue about how he was able to achieve such success was his strong acknowledgment of the help he received from the social worker at the nursing home and the county social workers, who filed Medicaid applications for his father and his grandmother. He said, "Well, I'll be honest. I'll be perfectly honest with you. When I went down to the Medicaid office, somebody was watching over me that day." Similar comments or testimonials regarding the assistance of others (social workers, physicians, nurses) were found in 8 of the 12 cases of high personal competence.

In summary, on one hand, there seems to be a relationship between low personal competence scores and time-pressured searches. On the other hand, high competence scores may be mediated by the help of others, regardless of the situational factors.

Perceived stress. The average stress score across all search categories was $11.44(S D=3.39)$ with a range of 5 to 16 . Female sponsors' stress scores averaged $12.36(S D=3.50)$ as compared to average scores of $10.27(S D=3.00)$ by their male counterparts ( $p=.14$, two-tailed tests). The stress scores for Whites (mean $=11.40, S D=3.72$ ) and Blacks (mean $=11.60, S D=1.82$ ) were essentially the same $(p=.90$, two-tailed test).

As might be expected, on average, stress scores tended to be higher for sponsors involved in time-pressured searches (mean $=12.05, S D=3.21$ ) than for sponsors engaged in non-time-pressured searches (mean $=9.86, S D=3.58$; $p=.08$ ). Once again, the availability of interview data provided insight into these differences. 
The sponsors with the three highest stress scores were all time-pressured searchers and had remarkably similar caregiving histories. All three sponsors were in caregiving roles at the time of the search, and each indicated that the role was exhausting, time consuming, or stressful. As described by the self-proclaimed burned out caregiving daughter whose father almost wrecked her car:

This man has lived 75 years and harsh as it is, I've decided I'm going to live again.... You feel guilty because you can't do everything they want. And then you look back and go, you know, "You're the biggest idiot that ever lived in this world." I mean the feelings are just so awful. . . . And now I'm happy that I made the decision to put him in the home.

Stress scores also tended to be higher, although not statistically significant, among sponsors who had engaged in anticipatory action (mean $=12.14$, $S D=3.30$ ) than for those who did not (mean $=10.54, S D=3.45 ; p=.13$ ). All three of the sponsors with the highest stress scores had engaged in anticipatory action prior to the nursing home placement. Their qualitative responses demonstrated that the sponsors' levels of stress may also be mediated by the presence or absence of helpful others. A 48-year-old woman who, prior to making the institutionalization decision, was helping her mother remain in her own apartment by providing meals and doing light chores, began her story by explaining the mounting stress associated with her caregiving arrangement.

I have feelings of resentment toward my brother and sister sometimes. I don't think they realize the overwhelming responsibility. It's just that I happen to be here and he [the brother] lives in a different city and if she lived with them it would be different. It's like if we want to go away we, which we did for four days, we have to set up a baby sitter ... ahead of time and to prepare her that we were going to be gone. Whereas my sister can take off and go or my brother can take off and go and they don't, it's not like you have to prepare her for that.

The daughter went on to explain that she and her siblings had made inquiries about nursing homes because they knew their mother's condition was deteriorating. It was the family physician who insisted on 24-hour care after a hospitalization for congestive heart failure. The daughter recalled the experience as an "emotional roller coaster" and again mentioned the involvement of her siblings: "In terms of actual placement I guess it fell to me because they [the siblings] were, they didn't want to do it. But it was whatever you think is best." 
Three of the six lowest stress scores, all below a score of 10 , were associated with dyadic relationships that did not include an adult child, daughter- or son-in-law, or a spouse as the sponsor; those individuals most often considered to be on the front line of long-term care decision making. A 72-year-old woman who was searching on behalf of her 81-year-old sister, offered this insight into her low level of stress.

\begin{abstract}
Well, I have a short story to tell you because she was in the hospital for 5 weeks and they got to where they said there was nothing else they could do. Therefore, she still had to have skilled care; she would have to be put in a nursing home for 30 days at least. ... So, I came home and went over there, and talked to [the Admissions Director at a nursing home], and they checked her in. And we moved her the next day. The rescue squad brought her the next day and that is all it was.
\end{abstract}

The sister explained that she and her husband were the only kin available to make the selection for her sister. The only facility she considered was the one closest to home. This sponsor was satisfied with her choice, a bed was available, and she met her obligation to her sibling. Her level of stress was minimal, despite the fact that hers was a nonanticipatory-time-pressured search.

To follow up on the idea that stress scores may be related to the relationship of the sponsor to the nursing home resident, regardless of the situational factors involved, we compared stress scores for spouse and nonspouse sponsors and for parent versus nonparent residents. Other comparisons were not possible, given the sample size. Stress scores for sponsors who were searching on behalf of a parent or parent-in-law were not significantly different (mean $=12.08, S D=3.77$ ) from sponsors who were searching on behalf of individuals such as a sibling or friend (mean $=10.75, S D=2.93$; $p=.34$, two-tailed test). The stress scores of sponsors who were spouses of the care recipients (mean $=11.80, S D=1.92$ ) were similar to the scores of nonspouse sponsors (mean $=11.35, S D=3.70 ; p=.80$, two-tailed test). Therefore, the two comparisons did not support the hunch that relationship played a key role in these sponsors' levels of stress.

To summarize the findings about sponsors' stress scores, time-pressured searches are related to sponsors' higher stress. Anticipatory action is related to high stress; however, it is important to consider the caregiving context at the time the search begins (e.g., long-term caregiving with poor social support from others) to understand the relationship between the variables. 


\section{Discussion}

In this study we examined the experiences of sponsors searching for and selecting nursing homes on behalf of others and described four groups of distinctly different situations (with and without time pressures and with and without prior anticipatory action) that result in varying degrees of perceived personal competency and personal stress among the sponsors. Of particular interest to those who work with these sponsors are the findings that searchers who engaged in anticipatory behavior had lower personal competence scores than those who did not, and time-pressured searchers had higher stress scores than their non-time-pressured counterparts.

The long-term care system is notoriously complex and confusing-with its own language, multiple reimbursement mechanisms, and often laborious eligibility requirements. It may be the case that competency scores for those sponsors who engaged in anticipatory behavior were lower than for those sponsors who had not because the more sponsors think and learn about the long-term care system, the more complex the process becomes to them. The more they know, the more they feel they do not know. How could they feel well informed when there was so much to learn? How could they do everything they could when there was always something else to do? In contrast, those sponsors who made placement decisions without prior searching and information-gathering behavior may have felt that they did the best they could (higher personal competence) under the circumstances.

There is also anecdotal evidence in the qualitative data that sponsors who reported very low perceived competence were under the greatest stress as primary caregivers at the time of the search. For these sponsors, anticipatory behavior apparently did little to reduce the overall stressful nature of their caregiving situation and the search and selection process that was inevitable.

Discharge planners, case managers, and others who work with sponsors engaged in the nursing home search and selection process may be able to improve sponsors' perceptions of personal competence by sheltering them from information overload. Suggesting ways in which the sponsor can order and prioritize searching tasks from simple to complex, to the extent possible, may also permit greater competence building to occur. The content of printed educational material should also follow a format of simple to complex information and immediate versus later tasks to be accomplished. The results also indicated that even a little help by professionals was very important.

Among this study's sponsors, personal competence was not affected by time pressure (the immediacy of their need to place the care recipient in a 
nursing home). In future studies, it would be useful to have a larger sample so that very short time pressures (a matter of days) could be distinguished from longer time pressures (involving a few weeks to months) and searches that result from hospitalization could be distinguished from those that are other time-pressured situations.

Time pressures did, however, have a significant effect on sponsors' levels of stress. The chilling account of the elderly woman who was discharged with an open abdominal wound without prior warning to her husband is clearly an extreme example of discharge planning run amok. Nevertheless, it does underscore the immediate and long-term stress that current health care policies can place on families and friends of older adults in need of institutional long-term care. Sadly, it appears that the sponsors did not complain, did not argue for their rights, and accepted the extraordinary stress and burden imposed by unrealistic time-pressured searches as the norm. Have consumers come to accept harsh treatment by hospitals and the health care system, in general, on matters related to long-term care?

Because this project focused on the experiences of the people who actually went about searching for and selecting a nursing home, we do not know how the care recipients felt or responded during the process. The occasional report by the sponsors on the care recipients' state of mind provided some insight. However, additional research is needed that examines such issues as the effect of the sponsors' stress on the care recipients and vice versa.

Increasingly, long-term care providers are reaching out to prospective clients with such innovations as Web sites on the Internet and service videos that can be played in the privacy of one's home. Not only do these strategies enhance public education and public relations, but they may very well become significant stress reduction mechanisms in the future for busy contemporary families who need to search for information or complete application forms at times when admission staff are not available. Imagine the convenience if a caregiver could watch a video about a nursing home or use the Internet to place the care recipient on a waiting list, fill out admission forms, or leave and receive messages without playing telephone tag. Yet, not one of the study sponsors reported using any of these technologies to aid in their search or selection processes.

In conclusion, none of the sponsors looked forward to or enjoyed their searches for an acceptable nursing facility. It is unlikely that any amount of education or intervention will change these affective elements of the process. However, with education and professional intervention, it may be possible to improve caregivers' perceived personal competence and reduce levels of stress associated with the process. 


\section{References}

Chenoweth, B., \& Spencer, B. (1986). Dementia: The experience of family caregivers. The Gerontologist, 26, 267-272.

Coulton, C. J., Dunkle, R. E., Haug, M., Chow, J., \& Vielhaber, D. P. (1989). Locus of control and decision making for post-hospital care. The Gerontologist, 29, 627-632.

Floyd, J. A. (1993). The use of across-method triangulation in the study of sleep concerns in healthy older adults. Advances in Nursing Science, I6(2), 70-80.

Freudenberger Jett, K. M., Coward, R. T., Schoenberg, N. E., Duncan, R. P., \& Dwyer, J. W. (1996). The influence of community context on the decision to enter a nursing home. Journal of Aging Studies, 10, 237-254.

George, L. K., \& Gwyther, L. P. (1986). Caregiver well-being: A multidimensional examination of family caregivers of demented adults. The Gerontologist, 26, 253-259.

Gonyea, J. G. (1987). The family and dependency: Factors associated with institutional decision-making. Journal of Gerontological Social Work, 10, 61-77.

Groger, L. (1994). Decision as process: A conceptual model of Black elders' nursing home placement. Journal of Aging Studies, 8, 77-94.

Holstein, M. (1995). Qualitative gerontology. Research on Aging, 17, 114-117.

Kane, R. L., \& Kane, R. A. (1989). Transitions in long-term care. In M. A. Ory \& K. Bond (Eds.), Aging and health care (pp. 217-243). New York: Routledge.

Lazarus, R. S., \& DeLongis, A. (1983). Psychological stress and coping in aging. American Psychologist, 38, 245-254.

McAuley, W. J., \& Travis, S. S. (1997). Positions of influence in the nursing home admission decision. Research on Aging, 19, 26-45.

McAuley, W. J., Travis, S. S., \& Safewright, M. P. (1997). Personal accounts of the nursing home search and selection process. Qualitative Health Research, 7, 236-254.

Noelker, L., \& Townsend, A. L. (1987). Perceived caregiving effectiveness. In T. H. Brubaker (Ed.), Aging, health, and family (pp. 58-79). Newbury Park, CA: Sage.

Pratt, C., Schmall, V., \& Wright, S. (1987). Ethical concerns of family caregivers to dementia patients. The Gerontologist, 27, 632-638.

Pratt, C., Schmall, V., Wright, S., \& Hare, J. (1987). The forgotten client. In T. H. Brubaker (Ed.), Aging, health, and family (pp. 197-213). Newbury Park, CA: Sage.

Reinharz, S., \& Rowles, G. D. (Eds.). (1988). Qualitative gerontology. New York: Springer.

Salamon, M. J., \& Rosenthal, G. (1990). Home or nursing home: Making the right choices. New York: Springer.

Stagner, R. (1981). Stress, strain, coping, and defense. Research on Aging, 3(1), 3-32.

Stephens, M. A., \& Hobfoll, S. E. (1990). Ecological perspectives on stress and coping in later-life families. In M. A. Stephens, J. H. Crowther, S. E. Hobfoll, \& D. L. Tennenbaum (Eds.), Stress and coping in later-life families (pp. 287-304). New York: Hemisphere.

Article accepted January 23, 1998

Shirley S. Travis is a professor of nursing at the University of Oklahoma Health Sciences Center, where she holds the Parry Endowed Chair in Gerontological Nursing. She received her bachelor's and master's degrees from Georgia State University and her 
Ph.D. from Virginia Polytechnic Institute and State University. Her research and publications have focused on discharge outcomes of frail or vulnerable elders from hospitals, psychiatric care, and nursing homes. She is currently involved in multiple projects that explore reimbursement, programming models, family support, staff training, and health care monitoring in adult day services.

William J. McAuley is a professor of health administration and policy and serves as cochair of the Oklahoma Center on Aging at the University of Oklahoma Health Sciences Center. He received his bachelor's degree from the University of North Carolina-Charlotte and his Ph.D. from The Pennsylvania State University. He is a former editor of the Journal of Applied Gerontology. His research interests include formal and informal long-term care, transitions in care needs and in caregiving, the demographics of long-term care, and ruralurban and minority issues in aging. He is currently investigating health and aging in Oklahoma's historical all-Black communities, as well as migration patterns to nursing homes in Maryland and Virginia. 